\title{
A BREZIS-NIRENBERG TYPE THEOREM ON LOCAL MINIMIZERS FOR $p(x)$-KIRCHHOFF DIRICHLET PROBLEMS AND APPLICATIONS
}

\author{
XIANLING FAN
}

Abstract. This paper deals with a class of $p(x)$-Kirchhoff Dirichlet problems possessing a variational structure which corresponds to the variational functional $E$ defined on $W_{0}{ }^{1, p(x)}(\Omega)$. We prove a Brezis-Nirenberg type theorem which asserts that every local minimizer of $E$ in the $C^{1}(\bar{\Omega})$ topology is also a local minimizer of $E$ in the $W_{0}^{1, p(x)}(\Omega)$ topology. Some applications of this theorem are given.

Mathematics subject classification (2010): 35J70, 58E30.

Keywords and phrases: Kirchhoff equation, $p(x)$-Laplacian, local minimizer, variational method.

\section{REFERENCES}

[1] E. Acerbi, G. Mingione, Regularity results for a class of functionals with nonstandard growth, Arch. Rational Mech. Anal., 156 (2001), 121-140.

[2] C. O. Alves, F. J. S. A. CORRÊA, On existence of solutions for a class of problem involving a nonlinear operator, Commun. Appl. Nonlinear Anal., 8 (2001), 43-56.

[3] C. O. Alves, F. J. S. A. CorrêA, T. F. MA, Positive solutions for a quasilinear elliptic equation of Kirchhoff type, Comput. Math. Appl., 49 (2005), 85-93.

[4] C. O. Alves, M. A. S. Souto, Existence of solutions for a class of problems in $\mathbb{R}^{N}$ involving the $p(x)$-Laplacian, Progress in Nonlinear Differential Equations and Their Applications, 66 (2005), $17-32$.

[5] S. Antontsev, S. Shmarev, Elliptic equations with anisotropic nonlinearity and nonstandard conditions, Handbook of Differential Equations, Stationary Partial Differential Equations, Vol. 3, Edited by M. Chipot and P. Quittner, Elsevier B. V., North Holland, Amsterdam, 2006, pp.1-100.

[6] G. Autuori, P. PuCCI, M. C. SAlVatori, Asymptotic stability for anisotropic Kirchhoff systems, J. Math. Anal. Appl., 352 (2009), 149-165.

[7] J. G. Azorero, J. J. Manfredi, I. P. Alonso, Sobolev versus Hölder local minimizer and global multiplicity for some quasilinear elliptic equations, Comm. Contemp. Math., 2 (2000), 385-404.

[8] H. Brezis, L. Nirenberg, $H^{1}$ versus $C^{1}$ local minimizers, C. R. Acad. Sci. Paris Ser. I Math., 317 (1993), 465-472.

[9] Y. Chen, S. Levine, M. Rao, Variable exponent, linear growth functionals in image restoration, SIAM J. Appl. Math., 66 (2006), 1383-1406.

[10] M. CHIPот, B. Lovat, Some remarks on non local elliptic and parabolic problems, Nonlinear Anal., 30 (1997), 4619-4627.

[11] F. J. S. A. CorrêA, G. M. FigueIredo, On an elliptic equation of p-Kirchhoff type via variational methods, Bull. Austral. Math. Soc., 74 (2006), 263-277.

[12] G. W. DAI, R. F. HAO, Existence of solutions for a $p(x)$-Kirchhoff-type equation, J. Math. Anal. Appl., 359 (2009), 275-284.

[13] G. W. DAI, D. C. LIU, Infinitely many positive solutions for a $p(x)$-Kirchhoff-type equation, J. Math. Anal. Appl., 359 (2009), 704-710. 
[14] L. DiEning, P. HÄstö, A. NEKVINDA, Open problems in variable exponent Lebesgue and Sobolev spaces, FSDONA04 Proceedings, (P. Drábek and J. Rákosník (eds)), Milovy, Czech Republic, 2004, $38-58$.

[15] M. Dreher, The Kirchhoff equation for the p-Laplacian, Rend. Semin. Mat. Univ. Politec. Torino, 64 (2006), 217-238.

[16] X. L. FAN, Global $C^{1, \alpha}$ regularity for variable exponent elliptic equations in divergence form, J. Differential Equations, 235 (2007), 397-417.

[17] X. L. FAN, On the sub-supersolution method for $p(x)$-Laplacian equations, J. Math. Anal. Appl., 330 (2007), 665-682.

[18] X. L. FAN, Q. H. Zhang, Existence of solutions for $p(x)$-Laplacian Dirichlet problems, Nonlinear Anal., 52 (2003), 1843-1852.

[19] X. L. FAN, D. ZHAO, A class of De Giorgi type and Hölder continuity, Nonlinear Anal., 36 (1999), 295-318.

[20] X. L. FAn, D. ZhaO, On the spaces $L^{p(x)}(\Omega)$ and $W^{k, p(x)}(\Omega)$, J. Math. Anal. Appl., 263 (2001), $424-446$.

[21] Z.M. Guo, Z.T. ZHANG, $W^{1, p}$ versus $C^{1}$ local minimizers and multiplicity results for quasilinear elliptic equations, J. Math. Anal. Appl., 286 (2003), 32-50.

[22] P. Harjulehto, P. Hëstö, , U. V. LÊ, M. NuOrtio, Overview of differential equations with nonstandard growth, Nonlinear Anal., In Press.

[23] X. M. HE, W. M. Zou, Infinitely many positive solutions for Kirchhoff-type problems, Nonlinear Anal., 70 (2009), 1407-1414.

[24] G. KiRChHOFF, Mechanik, Teubner, Leipzig, 1883.

[25] O. KovÁČIK, J. RÁKosNiK, On spaces $L^{p(x)}$ and $W^{k, p(x)}$, Czechoslovak Math. J., 41 (1991), $592-$ 618.

[26] J. L. Lions, On some questions in boundary value problems of mathematical physics, In Proceedings of International Symposium on Continuum Mechanics and Partial Differential Equations, Rio de Janeiro 1977, Math. Stud. (edited by de la Penha and Medeiros), pp. 284-346, vol. 30, North-Holland, 1978.

[27] T. F. MA, Remarks on an elliptic equation of Kirchhoff type, Nonlinear Anal., 63 (2005), 1967-1977.

[28] P. MARCELLINI, Regularity and existence of solutions of elliptic equations with $(p, q)$-growth conditions, J. Differential Equations, 90 (1991), 1-30.

[29] M. MIHĂILESCU, V. RĂDULESCU, A multiplicity result for a nonlinear degenerate problem arising in the theory of electrorheological fluids, Proc. Royal Soc. Lond. Ser. A, 462 (2006), 2625-2641.

[30] M. MiHĂILESCU, V. RĂDULESCU, On a nonhomogeneous quasilinear eigenvalue problem in Sobolev spaces with variable exponent, Proc. Amer. Math. Soc., 135 (2007), 2929-2937.

[31] K. Perera, Z.T. ZhAng, Nontrivial solutions of Kirchhoff-type problems via the Yang index, J. Differential Equations, 221 (2006), 246-255.

[32] B. RICCERI, On an elliptic Kirchhoff-type problem depending on two parameters, J. Global Optimization, Published online: 28 May 2009 (DOI: 10.1007/s10898-009-9438-7).

[33] M. RŮŽIČKA, Electrorheological Fluids: Modeling and Mathematical Theory, Springer-Verlag, Berlin, 2000.

[34] S. SAMKo, On a progress in the theory of Lebesgue spaces with variable exponent: maximal and singular operators, Integral Transforms and Special Functions, 16 (2005), 461-482.

[35] Q. H. ZHANG, Existence and asymmptotic behavior of blow-up solutions to a class of $p(x)$-Laplacian problems, J. Math. Anal. Appl., 329 (2007), 472-482.

[36] V. V. Zhikov, On some variational problems, Russian J. Math. Physics, 5 (1997), 105-116. 